\title{
曲面形状補間を用いた五軸制御加工用工具経路生成法*
}

\author{
森 川真 寿*1, 石田徹*2 \\ 寺本 孝 司*2, 竹 内芳 美*3
}

\section{5-Axis Control Tool Path Generation Using Curved Surface Interpolation}

\author{
Masatoshi MORIKAWA, Tohru ISHIDA, \\ Koji TERAMOTO and Yoshimi TAKEUCHI*4
} ${ }^{* 4}$ Department of Computer-Controlled Mechanical Systems, Graduate School of Engineering, Osaka University,
2-1 Yamadaoka, Suita-shi, Osaka, 565-0871 Japan

\begin{abstract}
In 5-axis control machining, it is important to reduce the processing time of generating interference-free tool path between tool and workpiece. Thus, the paper describes a method to determine interference-free tool postures, based on not every cutting point but every tool path. The method generates a ruled surface between an offset curve which sifts a cutting point curve by a tool radius against a surface to be machined, and one of parametric curves on an interference surface. A boundary tool locus which does not interfere with workpiece is generated by rotating the ruled surface, while moving control points on the surface. Tool postures corresponding to a cutting point curve are determined by appropriately selecting the curve within an area surrounded by two ruled surfaces. The curve implies a candidate of interference-free tool paths can be generated at high speed. The effectiveness of the proposed method was demonstrated by machining experiment of an impeller.
\end{abstract}

Key Words : 5-Aixs Control Machining, Interference-free, Tool Path, Curved Surface Interpolation, CAM

\section{1. 緒 言}

近年, 製造業界では製品の多様化および複雑化に伴 って, 設計・製造工程における工程数の増加が問題と なってきている。これに対して, 製造工程を集約する ことで効率的な生産を実現するべく，多軸制御加工機 や複合加工機が注目を集めている，その中でも五軸制 御加工機は, 工具や加工物の段取り替え省略による工 程数削減などが可能なことから導入が盛んになってい る.

五軸制御加工では, 加工物に対する工具姿勢の自由 度が高いため, オーバハング部を有する複雑な形状も 加工物を再セッティングすることなく加工できる。こ のことは, 再セッティングに伴う誤差が生じないなど の利点がある. しかしながら, 工具姿勢の自由度の高 さに起因した, 工具と加工物間の干涉が問題となって いる。

現在, 五軸制御加工用 CAM がいくつか開発されて いるが, 工具の干渉問題のために加工対象が限定され

\footnotetext{
* 原稿受付 2005 年 3 月 31 日.

*1 大阪大学大学院生 ( 565-0871 吹田市山田丘 2-1).

*2 正員, 大阪大学大学院工学研究科.

*3 正員, フェロー, 大阪大学大学院工学研究科.

E-mail : takeuchi@mech.eng.osaka-u.ac.jp
}

るなどその機能に制限があるため, 多様化した複雑な 製品への適用は容易ではない(1). 五軸制御用 CAM で の干涉回避に関する研究では, 代表的な切削位置ごと に工具と加工物との干渉を検出し，干渉があれば局所 的に工具姿勢を変化させて回避するといったものが主 流である(2)(3).これらは全切削位置ごとに工具と加工 物間の干渉検出を行い, 干涉があれば干渉回避した工 具姿勢を決定するという試行錯誤的な処理を行ってい る. 複雑な形状に対しては, C-Space という概念を導 入し, 干涉を巧妙に回避する方法も開発されている(4) が, 多くの計算時間を要し, 高効率な CAM システム としての実用性には難がある.したがって, 信頼性が 高く, 短時間で工具経路生成が可能な CAM の開発が 望まれている。

そこで本研究では, ボールエンドミル工具を用いた 五軸制御加工において, 干涉のない工具経路を高速に 生成することを目的とした新たな工具経路生成手法を 提案する，具体的には，工具姿勢を切削点ごとに決定 するのではなく, 工具掃引形状の中心軌跡を曲面形状 を用いて補間し，一つの工具経路ごとに工具姿勢の取 りうる領域を求める. その領域から工具姿勢を決定す ることで, 干渉のない工具経路を生成する.

提案した手法を実装した五軸制御加工用メインプロ 
セッサを開発し, 複雑形状であるインペラを加工対象 形状として加工実験を行い, その手法の有効性を検証 したので報告する.

\section{2. 工具経路の曲面形状補間}

$2 \cdot 1$ 工具経路における用語の定義 本研究では, 工具経路を生成する際に使用する形状要素である点, 曲線，曲面を図 1 に示すように定義する。ボールエン ドミル工具の刃が加工面に接するときの切削位置を切 削点, 切削点を工具送り方向に補間した軌跡曲線を切 削線, 工具中心点を工具送り方向に補間した軌跡曲線 を工具中心曲線とする. 工具姿勢を表す工具軸べクト ルを工具送り方向に張った曲面を工具軸曲面, 工具軸 ベクトルの先端を結んだ曲線を工具軸曲線と呼ぶ.

\section{$2 \cdot 2$ 工具姿勢の曲面形状補間}

$2 \cdot 2 \cdot 1$ 法線方向工具経路の生成 加工面に対し て自由度の高い工具姿勢を実現するために, まず加工 面上の一つの工具経路上に工具軸曲面を生成する. 図 1 を用いてその手順を述べる.

最初に, 加工面に対して法線方向に工具半径だけオ フセットした曲面を生成する，オフセット曲面をピッ クフィード方向に分割した曲線が工具中心曲線とな る. 次に, 工具中心曲線をオフセット曲面の法線方向 に工具長だけ伸長した曲線を生成する。この曲線が加 工面に対して法線方向の工具姿勢となる工具軸曲線で ある. 続いて, 生成された工具中心曲線と工具軸曲線 の 2 曲線間にルールド曲面を生成する。このルールド 曲面は, 工具送り方向に工具軸ベクトルを張ったとき にできる工具軸曲面にほかならない.ここで, 工具姿 勢の制御を容易にするために, 工具軸曲面を構成する 2 曲線を NURBS 曲線で表す。

ここで, B-Spline の基底関数は, $m$ を階数, $n$ を制 御点数, $t_{i}$ をノットとして, 式(1)で定義される(5).

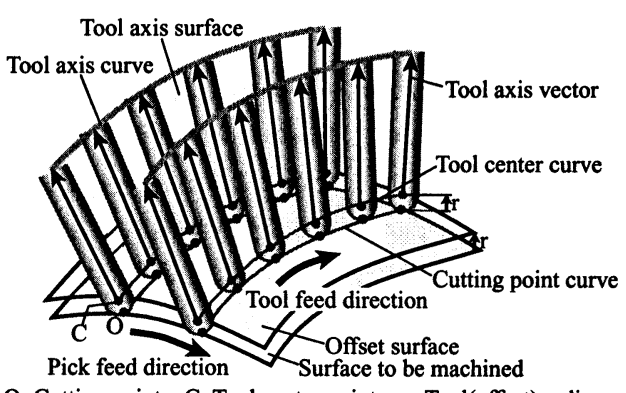

Fig. 1 Definition in tool path generation

$$
\begin{gathered}
N_{i, 1}(t)= \begin{cases}1 & \left(t_{i} \leq t<t_{i+1}\right) \\
0 & \left(t<t_{i}, t_{i+1} \leq t\right)\end{cases} \\
N_{i, m}(t)=\frac{t-t_{i}}{t_{i}+m-1-t i} N_{i, m-1}(t) \\
+\frac{t_{i+m}-t}{t_{i+m}-t_{i+1}} N_{i+1, m-1}(t)
\end{gathered}
$$

NURBS 曲線は，基底関数，座標空間における制御 点 $\boldsymbol{q}_{i}\left(x_{i}, y_{i}, z_{i}\right)$, 各制御点の重み $\omega_{i}$, 制御点 $\boldsymbol{Q}_{i}=$ $\left(\omega_{i} \boldsymbol{q}_{i}, \omega_{i}\right)(i=0, \cdots, n-1), ノ ッ ト ヘ ゙ ク ト ル \boldsymbol{T}=$ $\left[t_{0} \cdots t_{m+n+1}\right]$ を用いて, 式 $(2)$ で与えられる(5).

$$
\begin{aligned}
\boldsymbol{P}(t) & \equiv(x(t), y(t), z(t)) \\
= & \frac{\sum_{i=0}^{n-1} N_{i, m}(t) \omega_{i} \boldsymbol{q}_{i}}{\sum_{i=0}^{n-1} N_{i, m}(t) \omega_{i}}, t_{m-1} \leq t \leq t_{n}
\end{aligned}
$$

本研究では，曲線の扱いを容易にするために，すべ ての重みを $\omega_{i}=1.0$ とし, ノットの間隔を一様とす る. 加えて, NURBS 曲線にノットを挿入し, 多重化 することで曲線上の制御点を扱いやすくする.

元の NURBS 曲線のノットベクトル $\boldsymbol{T} に$ 対し, $k$ 番めと $k+1$ 番めのノット間に新たなノット $t^{\prime}$ を挿入 する場合, 新しいノットベクトル $\boldsymbol{T}^{\prime}$ は式（3)で表さ れる.さらにノットを挿入することで制御点の数が増 加し, 位置が変化する。それに伴う新たな制御点 $\boldsymbol{Q}^{\prime}(i=0, \cdots, n)$ は, 式( 4 ) で与えられる(5).

$$
\begin{aligned}
& \boldsymbol{T}^{\prime}=\left[t^{\prime} \cdots t_{m+n}^{\prime}\right]=\left[\begin{array}{lll}
t_{0} \cdots t_{k} & t^{\prime} & t_{k+1} \cdots t_{m+n+1}
\end{array}\right] \\
& t_{i}^{\prime}=\left\{\begin{array}{cl}
t_{i} & (0 \leq i \leq k) \\
t^{\prime} & (i=k+1) \\
t_{i-1} & (k+2 \leq i \leq m+n)
\end{array}\right. \\
& \boldsymbol{Q}_{i}^{\prime}=\left(1-\alpha_{i}\right) \boldsymbol{Q}_{i-1}+\alpha_{i} \boldsymbol{Q}_{i} \\
& \alpha_{i}=\left\{\begin{array}{l}
1 \quad(i \leq k-m+1) \\
\frac{t^{\prime}-t_{i}}{t_{i+m-1}-t_{i}}=\frac{t_{i}^{\prime}-t^{\prime}}{t_{i+m}^{\prime}-t_{i}^{\prime}} \quad(k-m+2 \leq i \leq k) \\
0 \quad(k+1 \leq i)
\end{array}\right\}
\end{aligned}
$$

扱う NURBS 曲線を, 三次の Bezier 曲線で構成さ れる複数のセグメントからなる曲線にする。そこで, 各セグメントの両端の制御点におけるノットの多重度 を階数 4 とし, それ以外のノットの多重度を 3 とす る.このように, 4 階の Bezier 形の NURBS 曲線に すると，制御点が曲線の端点から規制的に二つおきに 曲線上にのるために, $2 \cdot 2 \cdot 2$ 項で述べる制御点の移動 が扱いやすくなる。

図 2 に, NURBS 曲線に変更された工具中心曲線と 工具軸曲線の間に生成された工具軸曲面を示す。

2・2・2 制御点の移動による工具軸曲面の形状変化 五軸制御加工の利点は, 工具姿勢を自在に指定でき 
ることにある. 本研究では, 加工面に対して法線方向 に張られた工具軸曲面の形状を変化させ, 工具姿勢を 决定する.

五軸制御加工におけるボールエンドミル工具と加工 面との位置・姿勢の関係は, 一般に次のようになる. まず，工具中心点を原点として，加工面の法線べクト ル, 工具送り方向ベクトル，およびこれら二つのべク トルの外積で算出されるべクトルより構成される局所 座標系を考える。この系に扔いて，工具姿勢は法線べ クトルに対する傾斜角度 $\theta$ と法線べクトルに対する 回転角度 $\phi$ 二つのパラメータによって表現される。 ところで, 図 3 に示すように, 工具中心曲線㧍よび 工具軸曲線の 1 セグメントの制御点 $\boldsymbol{C}_{3 i}, \boldsymbol{C}_{3(i+1)}, \boldsymbol{P}_{3 i}$ および $\boldsymbol{P}_{3(i+1)}$ は曲線上にのっている。ここで, 前述の 考えに基づいて, $\boldsymbol{P}_{3 i}$ と $\boldsymbol{P}_{3(i+1)}$ を傾斜角度 $\theta$, 回転角

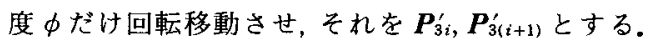
このときの移動ベクトルをそれぞれ $V_{3 i}, V_{3(i+1)}$ とす る.しかし, 制御点 $\boldsymbol{C}_{3 i+1}$ および $\boldsymbol{C}_{3 i+2}$ は工具オフセ ット曲面の工具中心曲線上にないため，その点におけ る法線ベクトルと第 1 階微分ベクトルが正確に算出で きない.したがって，工具軸曲線上にない制御点 $P_{3 i+1}$ と $P_{3 i+2}$ の移動べクトル $V_{3 i+1}, V_{3 i+2}$ は, 式(5) に示すように $V_{3 i}$ と $V_{3(i+1)}$ を用いて補間する。

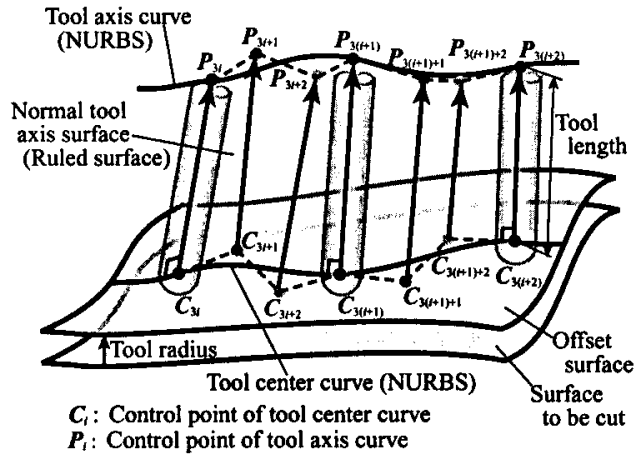

Fig. 2 Curved surface interpolation of normal tool axes

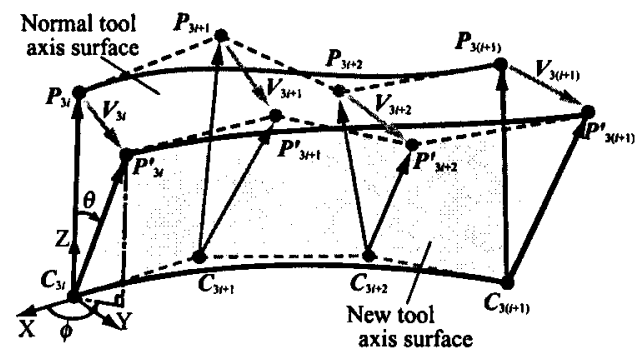

Fig. 3 Surface shape modification by moving control points

$$
\left.\begin{array}{l}
V_{3 i+1}=\frac{2}{3} V_{3 i}+\frac{1}{3} V_{3(i+1)} \\
V_{3 i+2}=\frac{1}{3} V_{3 i}+\frac{2}{3} V_{3(i+1)}
\end{array}\right\}
$$

算出された移動ベクトル $V_{3 i+1}^{\prime}, V_{3 i+2}$ により, 工具 軸曲線上にない制御点 $\boldsymbol{P}_{3 i+1}, \boldsymbol{P}_{3 i+2}$ はそれぞれ $\boldsymbol{P}_{3 i+1}^{\prime}$, $\boldsymbol{P}_{3 i+2}^{\prime}$ に移動する。

このように, 工具軸曲線の全セグメントに対して制 御点の移動を行うと，新たに生成された工具軸曲面は 設定した工具姿勢の工具軌跡として生成される。な お，加工面以外に干涉面が存在する場合は，工具姿勢 を自由に設定できない，3章では，干涉面を考慮した 工具経路生成法について述へる。

\section{3. 干渉を回避した工具経路生成法}

3・1 干渉面に沿った工具経路 工具と加工物が 干渉しない工具経路を生成する手法の一つとして, 図 4(a)に示すように, 加工物の表面に沿って工具姿勢 を変化しながら移動することが考えられる．以下で は，この考えに基づいて干涉のない工具経路を生成す る.すなわち，図 4(b)に示すように，干涉面の形状 を用いて干涉の有無の境界となる工具姿勢を表す曲面 (境界曲面)を作成し，それを利用して干涉せずに工具 軸曲線が取りうる領域を作成する。その領域内におい て，工具軸曲線を決め，それより工具姿勢を求めれば， 干渉のない工具経路を生成できる。

本手法では，干涉判別と干涉回避という試行錯詔的 な処理が不必要になるため，工具経路生成に要する計 算時間を大きく短縮できると考えられる。

3.2 干涉面による境界曲面の作成法 工具干涉 の有無の境界となる工具姿勢を作成するため，まず， 加工物の干涉面群の中で工具掃引形状軌跡を沿わせる 干涉面を選択する。図 5 の左に示すように，選択され た干涉面上の分割された曲線群中より，工具中心曲線 から見て干涉面上で最も大きな凸部を有する曲線を自



(a) Boundary surface when the tool moves along the interference surface

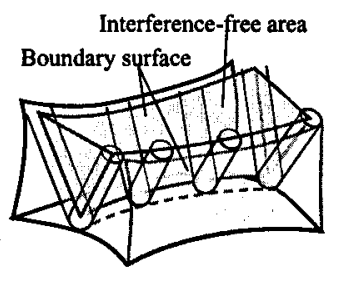

(b) Interfaerence-free area of tool path

Fig. 4 Tool path generation method 
動選出する．この曲線が工具姿勢変化の基となる．こ の曲線と工具中心曲線との間にルールド曲面を生成す る.このルールド曲面を構成する 2 曲線も 4 階 Bezier 形 NURBS 曲線とする。

次に, 工具半径を考慮に入れて境界曲面を構成す る. 生成されたルールド曲面を構成する工具中心曲線 と干渉面上の曲線との間で, 曲線上にのっていて, 対 応する制御点 $C_{3 i}$ と $P_{3 i}$ を結ぶベクトル $\boldsymbol{T}$ (制御点間 ベクトル)を考える.ここで, 任意のベクトル $V$ を回 転軸として角度 $\Psi$ の回転移動を表すマトリックスを $\operatorname{Rot}^{(\boldsymbol{V})}(\Psi)$ とすると, 干涉面との境界となる $3 i$ 番め の制御点間べクトル $\boldsymbol{T}^{\prime}$ は, 図 5 の右に示すように, 式(6)のように算出される.ただし, 回転方向は干渉 面より遠ざかる方向とする.

$$
\boldsymbol{T}^{\prime}=\boldsymbol{T R o t} \operatorname{tr}^{(\boldsymbol{T} \times \boldsymbol{N})}(\Psi)
$$

ここで, $\boldsymbol{N}$ は制御点 $\boldsymbol{P}_{3 i}$ における干渉面の法線べク トルである. また， $\Psi$ は工具半径 $r$ を用いて式 $(7)$ より算出される。

$$
\Psi=\sin ^{-1} \frac{r}{|\boldsymbol{T}|}
$$

この回転移動を, 曲線上にのっている $3 i$ 番めの制 御点に対して行う. 曲線上にのっていない $3 i+1,3 i$ +2 番めの制御点は, $2 \cdot 2 \cdot 2$ 項で述べたように移動べ クトルを補間して回転移動を行う.

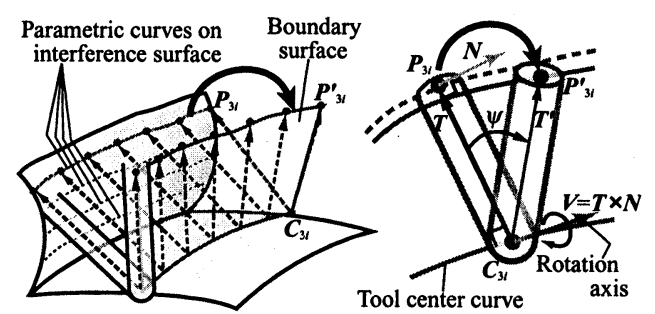

Fig. 5 Boundary surface generation by moving control points on the initial ruled surface

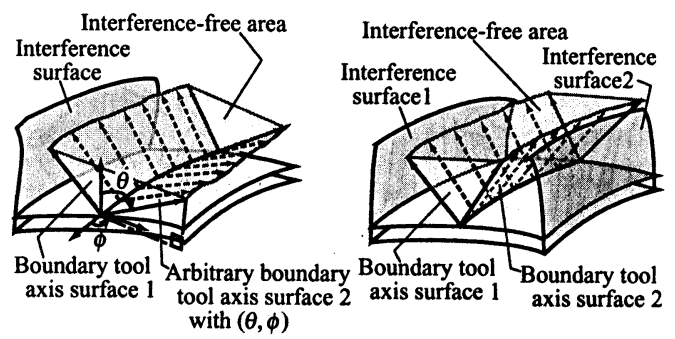

(a) Boundary surface at case 1

(b) Boundary surface at case 2

Fig. 6 Interference-free area between boundary surfaces

以上の処理で得られたルールド曲面が，干渉面と干 涉しない工具掃引形状の中心軌跡を表す境界曲面とな る.

$3 \cdot 3$ 加工面を考慮した境界曲面の作成法 周囲 の干渉面に対しては, $3 \cdot 2$ 節の干渉境界曲面を作成し たが，加工面に対する干涉は考慮されていない.そこ で, 加工面に対する工具干涉も考慮するために, 加工 面に対して干涉の有無となる境界曲面を 2 章で述べた 手法を用いて作成する.図6(a)に示すように, 傾斜 角度 $\theta$, 回転角度 $\phi$ を設定することで加工面に対して 干涉のない工具軌跡を表す境界曲面を作成する．ただ し, 設定した境界曲面と加工面との距離が工具半径以 下になる可能性がある場合は, 傾斜角度に大きな值を 設定できない.

$3 \cdot 4$ 工具姿勢決定法 干涉のない工具軸曲線の 取りうる領域を作成する. 図 6(b)に示すように, 両 側に壁のある領域を加工するときには，まず，一つの 工具中心曲線において, 生成された二つの干涉面に対 する境界曲面のシャンク側の稜線をそれぞれ取出す. 次に, 2 稜線間にルールド曲面を作成する。このルー ルド曲面は, 一つの工具経路において, 工具中心曲線 に対応する干涉のない工具軸曲線が取りうる領域を表 している(以下, 非干涉領域という).この領域から工 具軸曲線を選出することで工具姿勢が決定され, 工具 経路を生成できる.

工具軸曲線の選出にあたって, 図 7 に示すように, まず, 生成された非干涉領域に局所座標系 $u-v$ を設 定する. 次に, 非干涉領域から $v$ 方向のパラメー夕值 を与えて工具姿勢となる工具軸曲線を選出する.ここ では, パラメー夕值を最も安全な工具姿勢となるよう に中間值をとって 0.5 とした. 最後に, 工具中心曲線 と選出された工具軸曲線間にルールド曲面を作成する と, 一つの工具経路について工具軸曲面が得られる。

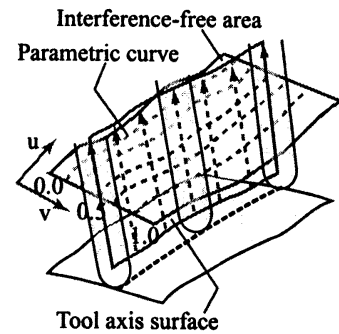

Fig. 7 Selection of tool axis curve within interference-free area

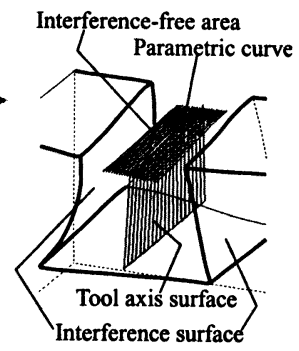

Fig. 8 Interference-free area and tool axis surface $($ parameter $=0.5)$ 
工具軸曲面を工具送り方向にパラメトリック分割し て得た各直線が工具軸べクトルに，その下端点が工具 中心点となる，本手法の適用例を図 8 に示す. 溝形状

Table 1 Cutting conditions

\begin{tabular}{l|c|c}
\hline Material of workpiece & \multicolumn{2}{|c}{ Aluminum (A2017) } \\
\hline & Roughing & Finishing \\
\hline Spindle speed (rpm) & 2500 & 12000 \\
\hline Feed rate (mm/min) & 800 & 500 \\
\hline Pick feed (mm) & 1.5 & $0.08 \sim 0.4$ \\
\hline Depth of cut (mm) & 1.0 & 0.3 \\
\hline
\end{tabular}
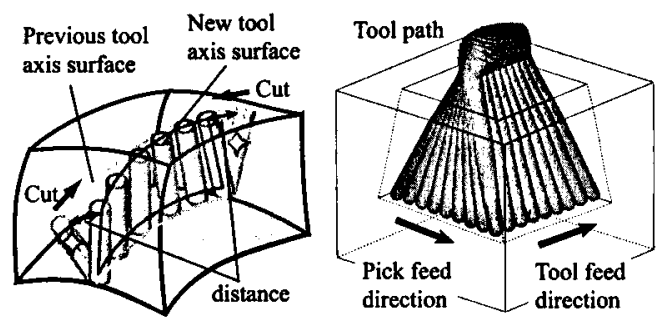

Fig. 9 Interference avoid- Fig. 10 Tool path surance in tool feed direction rounded by interference surfaces



Fig. 11 Workpiece shape to be machined: Impeller

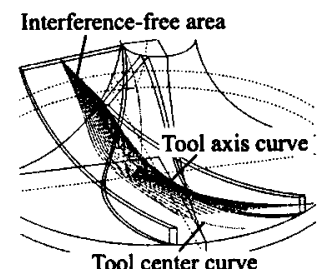

Fig. 12 Tool path generated on hub surface
の底面を加工面として，一つの工具経路における非干 涉領域と，そこから得られた工具軸曲面である。

一般に見られるような工具送り方向の耐側に存在す る干涉面に対しては，以上のような工具経路生成法に よって，干涉のない工具経路を生成できる。しかし， ポケット形状のように工具進行方向にも干涉面が存在 する場合には，進行方向の干涉についても検討する必 要がある。この対策として, 作成された工具軸曲面の 形状をさらに変化させることで干涉回避を行う。

そこで, 図 9 に示すように,まず, 作成された工具



Fig. 14 Appearance under finish machining

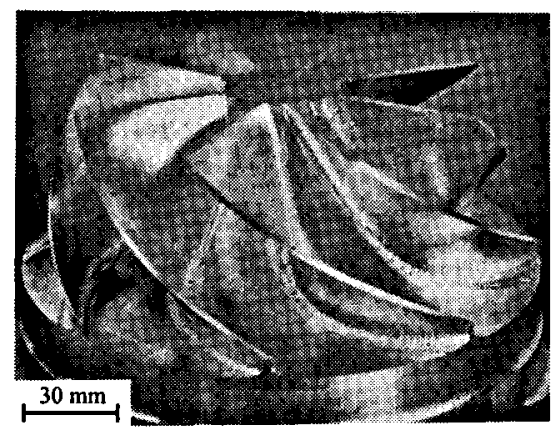

(a) Over view

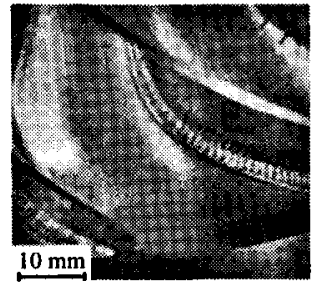

(b) Hub surface

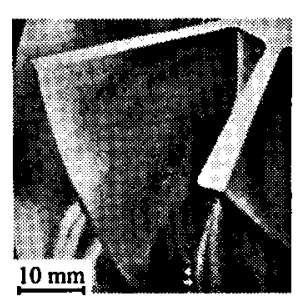

(c) Suction surface
Fig. 15 Machined result of impeller 
軸曲面内の工具軸と工具送り方向の干涉面との距離を 算出する。その距離が工具半径以下の場合には, 工具 半径以上の適当な距離となる位置で工具軸曲線を切断 する．切断した工具軸曲線と工具中心曲線間に新たな 工具軸曲面を作成すれば, 工具送り方向にも干涉のな い工具経路を生成できることになる.

この手法を適用して, 周囲を干渉面に囲まれたポケ ット形状の底面の加工用工具経路を求めた。 図 10 は, 得られたCutter Location Data(以下, CLデータと いう)から工具モデルを表示したものであるが，工具 送り方向, ピックフィード方向ともに工具と加工物と の干渉がないことが確認できる.

なお，干渉面がさらに多くなった場合には，処理上， 複数の干涉面を一つの干渉面として扱えるような前処 理をした上で，上記の手法を適用すればよいと考えて いる.

\section{4. 複雑形状を対象とした加工実験}

4・1 加工対象形状 本研究で提案した曲面形状 補間を用いた工具経路決定法を五軸制御加工用メイン プロセッサに実装し，その実用性を加工実験により検 証する. 加工対象形状は, 図 11 に示すような自由曲 面状のブレードを 8 枚有するようなインペラである. 従来，インペラは鋳造で製造されていたが，近年，圧 縮比を高くするため高速回転が生流となり, 強度上の 理由と圧縮効率を向上させるため, ブレードの削り出 し加工が多くなってきている. 加工実験では, 図 11 に示す四つの面の仕上げ加工を対象とした。

$4 \cdot 2$ 工具経路生成 本研究における荒加工の CL データは，インペラの荒加工用に別途に作成した システムを用いて作成した。仕上げ加工では, 開発し た五軸制御加工用メインプロセッサを用い，インペラ を構成する四つの面を加工面とした CL データをそれ ぞれ作成した，切削条件は表 1 に示すように設定し た. Hub surface に対するCL デー夕作成の際に, 一 つの工具中心曲線に対して生成された非干渉領域とそ の領域より得られた工具軸曲線を図 12 に示す。この 工具軸曲線を用いて生成された CL データの一部に工 具を表示した工具軌跡を図 13 に示す. 工具は両側の ブレードと干渉することなく, それらに沿って移動し ていることが確認できる.

Hub surface に対するCL デー夕生成時間を比較し
たところ，切削点における工具姿勢と加工物の干渉判 定を基に逐次的に干涉回避を行う従来の手法では約 55 分であったが, 本手法では約 12 分であり, 計算時 間を大幅に短縮できた。

$4 \cdot 3$ 加工結果 作成した CL データをポストプ ロセッサにより NCデータに変換し, 五軸制御マシニ ングセンタを使用して加工を行った。加工中のようす を図 14 に，加工結果を図 15 に示す．詳細な形状計測 が困難なため定量的な評価は行えないものの, CAD で設計した形状を，工具干涉することなく良好に加工 することができた。他の面に関しても比較的長好な面 性状が確認された。しかしながら，各曲面の境界に削 り残しが見られたが、これは作成した CLデータでこ れらの境界部分において工具が離脱する点となってい たからである．境界部分に沿って切削するような CL データを別に作成することで，このような削り残しは 解消できると考えられる。

\section{5. 結}

五軸制御加工における工具経路の生成処理の高速化 を目的とし，曲面形状補間表現を基にした工具経路生 成法を提案した。さらに，提案した手法を実装した五 軸制御加工用メインプロセッサを開発し，インペラに 対するCL デー夕を作成して加工実験を行ったとこ ろ, 工具干涉もなく良好な面性状を持つ加工結果が得 られ，提案した手法の有用性が示された。

本研究を実施するに当たり，五軸制御マシニングセ ン夕を貸与された MTTRF (工作機械技術研究財団) に感謝する。

\section{文献}

(1) Young, H.-T., Chuang, L. C-., Gerschwiler, K. and Kamps S., : A fiveaxis rough machining approach for a centrifugal impeller, Int. J. of Adv. Manuf. Technol., 23 (2004), 233-239.

（2）竹内芳美 - 清水弘幸 - 出村健 - 渡辺隆弘 - 伊藤哲也, ソ リッドモデルに基づく 5 軸制御加工, 精密工学会誌, 56 11 (1990), 2063-2068.

（3） 小西和正・福田好朗・岩田一明, 5 軸制御加工における工 具干涉検出と回避法に関する研究，精密工学会誌，63-9 (1997), 1258-1262.

（4）森重功一・竹内芳美, C-Spaceに基づいた 5 軸制御加工 における工具姿勢の決定法, 精密工学会誌, 66-7 (2000), 1140-1144.

（5）三浦曜・望月一正， $\mathrm{CAD} / \mathrm{CG}$ 技術者のための実践 NURBS (Non-Uniform Rational B-Spline), (2001), 工 業調査会. 